\title{
A Study on Flow Theory and Translation Teaching in China's EFL Class*
}

\author{
Xiaowei Guan \\ School of Foreign Languages, Dalian University of Technology, Dalian, China
}

\begin{abstract}
Flow or flow experience, a positive psychology concept, is characterized by intense focus, cognitive efficiency, a perceived skills-challenge balance, immediate feedback, merging of action and awareness, a sense of control, enjoyment, the opinion that time passes quickly, clearly defined task objectives and a lack of selfconsciousness. The application of flow theory in foreign language teaching is a new subject worth studying. The concept and components of flow, the conditions that flow occur, flow model and its application are introduced. The flow model and the principles in creating and achieving flow in foreign language teaching and learning is then presented. Flow theory is later applied in translation teaching, in which the translation course design and task requirement, the translation teaching and learning environment, learners' performance and the roles of learners and teachers are discussed. Flow experience emerged from the well-designed translation tasks will significantly improve the students' English learning intrinsic motivation and overall level. In the design of the translation teaching syllabus and students' translation tasks, teachers should have the "flow state" into consideration, in order to make the effect of translation teaching reach optimization.
\end{abstract}

Index Terms - flow theory, translation teaching, flow experience, optimal experience, foreign language teaching

In 2004, the Ministry of Education of China promulgated the "College English Curriculum Requirements (For Trial Implementation)" (2004) which marks the beginning of a new round of college English teaching reform. "College English Curriculum Requirements" (2007) specified that the goal of college English teaching is to develop students' English language proficiency, so that they can communicate effectively in English in their future study, work and social interaction. Colleges and universities should improve the traditional teacher-centered teaching pattern, and put forward new tasks for teaching content and methods, which will make English teaching develop towards personalized, selflearning direction.

Translation teaching, as an important branch of applied translation, has long been a research focus for scholars at home and abroad. Traditional translation teaching mode, not attaching importance to students' autonomy, has gradually emerged drawbacks and is no longer suitable for the development of modern translation teaching. With the use of modern educational technology in the translation classroom teaching, teachers' teaching methods and media will be increasingly rich, and put forward higher requirement for teachers to organize the class. Therefore teachers should improve students' interest in learning, and pay attention to the reaction of the students to stimulate students' flow experience, allowing students to dedicate themselves to feeling the joy of knowledge accumulation, acquiring the professional quality of a successful translator.

\section{INTRODUCTION TO FLOW THEORY}

\section{A. Flow}

The notion of "Flow" was first proposed by famous American psychologist Mihály Csíkszentmihályi (1975) in his book "Beyond Boredom and Anxiety: Experiencing Flow in Work and Play" in 1975. "Flow, a positive psychology concept, is the mental state of operation in which a person performing an activity is fully immersed in a feeling of energized focus, full involvement, and enjoyment in the process of the activity, and has been widely referenced across a variety of fields" (Csíkszentmihályi, 1990).

In his work, "Flow: The Psychology of Optimal Experience" (Csíkszentmihályi, 1990), Csíkszentmihályi outlines his theory that people are happiest in a state of flow, in which people are so involved in an activity that anything else seems to be insignificant, and people are completely concentrated or absorbed with the task or activity.

The flow state is an optimal state of one's intrinsic motivation (Csíkszentmihályi, 1990), in which people are completely immersed in what they are doing. It is a feeling that everyone has sometimes, which is characterized by a feeling of great absorption, engagement, satisfaction, and skills, during which temporal concerns are usually ignored.(Csíkszentmihályi, 1990)

\section{B. Components of Flow}

\footnotetext{
* This work was supported in part by a grant from Teaching Reform Fund of Dalian University of Technology (No. MS201280), and the Fundamental Research Funds for the Central Universities (No. DUT10RC(3)46).
} 
Nakamura and Csíkszentmihályi (2009) identify the following nine factors of an experience of flow. (Wright, 2012)

(1) To have clear goals.

In many situations, there are conflicting requirements and sometimes it's unclear about what you should do. But in a flow experience, people have a clear aim and know well what to do next.

(2) To need immediate feedback to one's performance.

When you're in a state of flow, you know how well you're doing because you can get immediate feedback from others around.

(3) To reach a balance between challenges and skills.

If a challenge is too difficult for you own skills, you will get frustrated and depressed. But if a challenge is too easy, you will feel boring. In a flow experience, you will feel engaged but not overwhelmed by the challenge, characterized by a balance between your own skills and the demands of the tasks and activities.

(4) To merging action and awareness.

People often consider things that are not quite related to the current tasks. But in the flow, you will focus your attention on what you are doing.

(5) To concentrate on the present moment intensely and focusedly.

Because of your absorption in the activity, you only mind what's related to the task at hand, and you don't consider irrelevant things. With the focus on activities, uneasy feelings which can lead to anxiety and depression are set aside.

(6) To have a sense of self-control over the task or activity.

The possibility for learners to exercise control in learning, especially in difficult situations, is considered to be essential in the flow experience.

(7) To get a loss of reflective self-consciousness.

People often spend a lot of energy on how they seem to others. In a state of flow, you're so engaged in the activity that you will not care about yourself.

(8) To experience subjectively that time is altered.

Time flies when you're really involved in the activity. Time may also seem to slow down the time you are performing some activities or tasks in which you've practiced and developed a high degree of skills.

(9) To experience intrinsic rewarding in the activity, also referred to as "autotelic experience".

Some activities are done for people's own sake, because they will find the enjoyment in the experience like most art, music, or sports. Other activities are done for people's future goals, like things they have to do as part of their jobs. But some of these object-oriented activities can also become ends in themselves, and enjoyed for their own sake (Wright, 2012).

\section{Conditions for Flow}

A balance must be reached between the challenge of the task at hand and the performer's own skills. To achieve a flow state, if the tasks are too easy or too difficult, flow can't occur. Both the levels of skill and challenge must be high and matched; if they are low and matched, then apathy results (Csíkszentmihályi, 1997).

People cannot force themselves to enter a state of flow. It just happens. A flow state can be entered when performing any task, although it is most likely to occur when one is heart and soul performing a task for intrinsic purposes. (Csíkszentmihályi, 1988; Snyder\& Lopez, 2007)

Flow theory postulates three conditions in order to achieve a flow state: (Csíkszentmihályi, 2005)

(1) People must be involved in an activity with clear task aims.

(2) Clear and immediate feedback must be given to the task at hand, which will help people to discuss any changing requirements and allows them to adjust their performance timely to keep the flow state in them.

(3) People must have a good balance between the challenges of a task at hand and their skills, and must have selfconfidence in their own abilities to do the task.

\section{Flow Model}

In 1997, Csíkszentmihályi (1997) published a more scientific and reasonable flow model (as seen in Fig.1), which describes the relationship between the challenges of a task and people's skills. The figure shows a further aspect of flow, which is more likely to occur when the challenge of the task at hand is higher than the average (above the center point) and people have skills above the average (to the right of the center point (Csíkszentmihályi, 1988). The center point of the figure indicates the average levels of challenge and skill of the people in all activities performed in their daily life. The further from the center an experience is, the greater the intensity of that state of being (whether it is flow or anxiety or boredom or relaxation) (Snyder \& Lopez, 2007). 


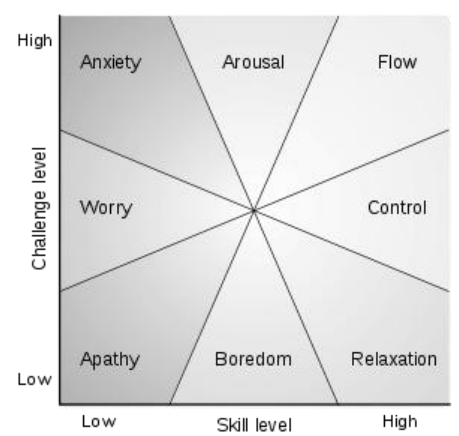

Figure 1. Csikszentmihalyi's flow model

\section{E. Applications of Flow Theory}

Recent studies show that Flow Theory is widely applied in the discussion of improving performance in areas as diverse as music improvisation, sport psychology, computer programming, and human-computer interaction (Parncutt \& McPherson, 2002; Young \& Pain, 1999; Webster, Trevino \& Ryan, 1993). Chan \& Ahern (1999) studied the theory of "flow" in education design. Theory and practice have proved that the "flow" experience exists in educational activities, such as reading and using a computer. Grabe and Stoller (1997) have suggested that in the language learning classroom, carefully planned teaching content will produce "flow". Abbott (2000) concluded that the "flow" experience can inspire learners to make language learning more efficient.

\section{Application of Flow Theory in Foreign Language Teaching AND Learning}

Foreign language learning is a complex cognitive activity involving variety of psychological phenomena, such as information identification, attention distribution, memory, and thinking (Lin, 2000). The application of Flow theory in the implementation of foreign language teaching can effectively develop learners' interest in learning, stimulate their' motivation, and effectively improve their participation in foreign language teaching. Optimal English input should arouse learners' interest in learning, which should be the exploratory materials attracting learners to learn continuously. During their exploration, attracted by the meaning and context, they forget the presentation forms of the input content, but knowing English input content directly.

\section{A. Flow Model in Foreign Language Teaching and Learning}

Figure 2 shows a model of the relationship between flow and language acquisition by Egbert (2003). The model suggested that the well-designed task and learners' skill in target language and tools can lead to flow. Flow, in turn, leads to learners' improved performance; then leads to changes in the learners' skills. In other words, although flow is individual experience not occurring in isolation; it depends on individual skills, the tasks the teachers assigned, the environment and other participants. In this model, the target language tasks take on a central play a very important role in the proposed relationship between flow and foreign language learning, which should be appropriate and interesting with clear goal. Learners will have control and can focus on the task, obtaining immediate feedback. Also in this model, skills are not limited to language modes (speaking, listening, reading, and writing), but include the use of tools such as computers or networks that may affect both flow and learning.

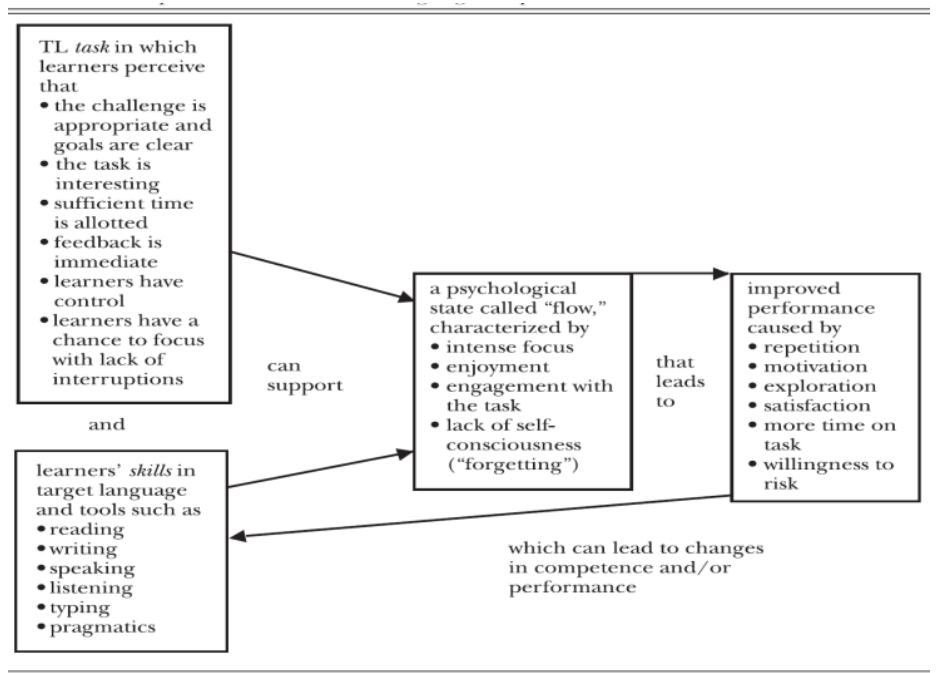

Figure 2. Model of the Relationship between Flow and Language Acquisition 


\section{B. Principles in Creating and Achieving Flow in Foreign Language Teaching and Learning}

(1) Task design in foreign language teaching and learning.

Flow theory requires teachers to provide clear, interesting, and achievable task. Clear goals and a balance between challenges and skills are very important.

In every step a clear goal is needed by learners, in order to stimulate learners' learning motivation. Interest is the main factor of motivation, is the positive reaction that the cognitive structure makes on stimulus, and can arouse and maintain the learners' curiosity.

An appropriate grasp of the balance between the difficulty of the tasks and the learners' skill levels can promote learners to achieve flow experience, to make learning achieve optimal effect.

(2) The environment in which the learning task completed.

Flow theory requires learners to reasonably distribute attention, eliminate interference, to achieve the optimal learning state. Learners need to concentrate on what you're doing. Time flies when you're really engaged. Students need certain independence without any interference from their teachers and classmates.

The task that can stimulate flow experience should be what learners think is important and meaningful, but must base on the premise that it will not produce anxiety.

(3) The performer of the learning tasks.

Learners need to only be aware of the task at hand and need to have a sense of self-control over the situation or the activity.

The learning process is also a process of internalizing the external information. Feedback is a kind of stimulation, and also continuous strengthening of information. Flow theory demands synchronous feedback in learning, that is, learners must be always aware of their progress, so as to constantly adjust learning objectives and plan, to produce flow experience. Immediate feedback is needed for one's actions, including teachers' feedback and students' feedback. We should also pay attention to the principal role of the participants.

\section{Translation Teaching And Learning With Flow TheOry}

Some scholars think that the flow model in foreign language teaching consists of three parts: flow antecedents, flow experience and flow consequences. (Chen, 1999; Hoffman \& Novak 1996)

Flow antecedents can be divided into three aspects: foreign language learning task, foreign language teaching and learning media and methods and foreign language learners. The teaching and learning media refer to computer assisted language teaching and learning based on modern information technology. The first two aspects will directly affect the third aspect, thereby affecting the flow experience and learning effects of learners.

To create flow experience, the following elements are required: (1) to determine a clear goal with controllable rules; (2) to create the opportunity to adjust activities to fit learners' potential; (3) to provide learners with accurate information on how to operate; (4) to shield from interfering factors, allowing learners to concentrate. Therefore, in foreign language teaching and learning teachers should create opportunities suitable for learners' ability, on the basis of teacher-learner's interaction to create good teaching and learning environment.

Flow experience will lead to the increase of learning behavior and the enhance of exploratory behavior, having a positive impact on foreign language learners, increasing learners' interest in learning foreign language and promoting the occurrence of repeated learning behaviors, so that learners are willing to spend more time on foreign language learning and upgrade their skills and abilities ultimately.

\section{A. Course Design and Task Requirement}

Teachers should make the task target in advance to avoid the waste or transfer of students' attention. Therefore, teachers need to carry out the pre-task preparation and mobilization to help students be familiar with and clear about the objectives. Teachers should have clear requirements for the translation tasks, for example the translation of a certain text style, so that students could think in this style, which will help students to concentrate, and avoid diffuseness and randomness.

Teachers should choose proper translation tasks. Too difficult or too many tasks will make students "overloaded", and produce anxiety, but too easy tasks may be dull, which can affect the balance between the challenge and students' skills. Therefore, teachers should choose tasks with appropriate degree of difficulty which won't give students too much pressure. For example, before assigning a task of translating an abstract of technical paper, teachers need to teach students the skills of word and sentence translation (English verb, noun, adjective, preposition, clauses, etc). With all these basic translation skills, students won't be afraid of the passage translation task too much. Moreover, teachers need to make clear the tasks, the target, and the content, letting students understand what to do, what kind of request to achieve, through which process. In the above example, teachers also need to explicitly tell students that in today's lesson the teaching goal is to learn the translation principles and skills of science and technology abstract, then they will be assigned a task on abstract translation.

Because of the network users most often enter into the flow state in information seeking situation, teachers could properly assign some tasks concerned with the teaching content. Learners need to inquire the tasks online, which will 
increase students' interest in learning English, so that they could enter the flow state. But this kind of tasks should be to be able to let students feel delighted, worthy and challengeable but can finish the tasks with efforts.

\section{B. Translation Teaching and Learning Environment}

Teachers must choose the tasks which the learners have a strong interest in, and refrain from interfering during task. Autonomy-supporting environments are most likely to generate flow in learners. Independent learning outside class which maximizes freedom to use their learning strategies will make students feel learning initiative, immersing in translation activities, maintaining a good motivation. What's more, in order to know students' level and organizing classroom with target, real-time monitoring and timely feedback is essential. In other words, teachers can use the LAN in multimedia classrooms conduct real-time monitoring of the translation process of the students, to control their translation process and provide timely comment.

As for the translation tools, a dictionary or electronic dictionary is not enough to meet the requirements of a professional translator. Network dictionary, parallel corpus, background knowledge base and other auxiliary facilities may create an authentic translation workshop, allowing students to meet the challenges with morale and enthusiasm and experiencing flow in the engrossed translation.

With the development of informatization of education, English teaching has undertaken great changes. Traditional English teaching consists of teachers, students, and teaching material; while in the modern teaching environment a new element - the teaching media — should be added. In the modern teaching environment (especially in network teaching environment), the "teaching content" is no longer limited to the traditional teaching material, but also includes tapes, videos, CNO courseware, multimedia courseware and various kinds of information resources from the Internet. Therefore, teachers could use all these means in their classroom teaching and instruct students to use all these means, especially the internet resource to help them with their tasks. Teachers can also design an online translation teaching and learning platform, on which lots of translation-related skills, knowledge or resources can be uploaded for students to search and learn. In addition, teachers can design an interaction forum, in which students can exchange ideas and with each other, and they can also be given immediate and non-evaluative feedback from their teachers and classmates. This kind of learning environment can sustain students' interest in learning and can be more natural to stimulate learners' flow experience, and they will be the main body of learning. Computer interface can help learners to focus on limited range through all sorts of different, novel, and surprising stimulation to arouse learners' learning curiosity to maintain lasting motivation.

\section{Learners' Performance}

When students are in a state of flow, they are working to master the activity at hand. They must seek increasingly greater challenges to maintain that flow state, and they will make their skills extended by attempting these new and difficult challenges.

In specific course, teachers need to have a goal for each step, being able to guide the students to move forward to the target step by step, to blur the boundaries of teachers and students, willing to be an assistant, to provide them with convenience as much as possible, so that they will complete teaching content in the ongoing exploration. Therefore the teaching of all the courses should be inspiring, student-centered and assisted by the teachers. Students will be more active in teaching activities in a relatively loose, autonomous environment to give full play to their skills.

Students in the same group need to have a sense of teamwork, cooperating with and assisting each other. Each group member needs to fulfill his own part of the task first, and then revise and proofread other's translation by giving immediate feedback.

\section{Roles of Learners and Teachers}

Teachers, as assists to the students participating in the challenge, need to fully understand the students' practical skill levels and provide challenge activities in line with their levels. Students, the main body of learning, need to complete the task independently under the teacher's guide so as to achieve an automatic state gradually.

Taking translation classroom exercises and after-school translation task for an example, teachers need to take full account of the actual levels of the students and their interest while choosing exercises and tasks which should be closely related to their lives to stimulate students' interest in learning. The exercises and tasks shouldn't be too easy or too difficult so as not to make students feel dull, tired, or anxious.

Teachers need to comprehensively understand their students, designing translation activities of moderate difficulty and being interest to students, arousing the imagination of students. Also they need to pay attention to their overall English level balances the level that activities require, spur them on to the generation of individuals flow and collective flow to promote English learning.

\section{CONCLUSION}

The quality of flow experience is characterized by intense focus, cognitive efficiency, a perceived skills-challenge balance, immediate feedback, merging of action and awareness, a sense of control, enjoyment, the opinion that time passes quickly, clearly defined task objectives and a lack of self-consciousness. 
The application of flow theory into translation teaching is a new attempt. In foreign language learning, students' flow experience depends on whether their skills and challenges are balanced, whether there is a clear learning objective, and whether they can get synchronous feedback on the process of task, excluding outside interference.

An appropriate translation task of practical texts could encourage students to enter a state of flow, experiencing pleasure in engrossing in the translation activities and a sense of accomplishment after the activities. Meanwhile, the flow experience emerged from the translation practice improves the students' English learning intrinsic motivation and overall level significantly.

Due to the experience of joy and satisfaction in learning, learners will continue to repeat to complete tasks, and their learning motive will be stronger and will put in more time, willing to challenge more difficult tasks.

\section{ACKNOWLEDGMENT}

This work was supported in part by a grant from Teaching Reform Fund of Dalian University of Technology (No. MS201280), and the Fundamental Research Funds for the Central Universities (No. DUT10RC(3)46).

\section{REFERENCES}

[1] Abbott, J. (2000). "Blinking out" and "having the touch": two fifth-grade boys talk about flow experiences in writing. Written Communication, (17): 53-92.

[2] Chan, T. S. and T. C. Ahern. (1999). Targeting motivation-adapting flow theory to instructional design. Journal of Educational Computing Research, 21(2), 151-163.

[3] Chen, H., Wigand, R. T. and Nilan, M. S. (1999). Optimal experience of web activities. Computers in Human Behavior, 15: 585-608.

[4] Csíkszentmihályi, M. (1975). Beyond boredom and anxiety: experiencing flow in work and play. San Francisco, CA: JosseyBass.

[5] Csíkszentmihályi, M. (1990). Flow: the psychology of optimal experience. New York: Harper and Row.

[6] Csíkszentmihályi, M. (1997). Finding flow: the psychology of engagement with everyday life. New York: Basic Books.

[7] Csíkszentmihályi, M. (1988). The flow experience and its significance for human psychology. In Csikszentmihalyi, M. (ed.), Optimal experience: psychological studies of flow in consciousness. Cambridge: Cambridge University Press.

[8] Csíkszentmihályi, M., Abuhamdeh, S. and Nakamura, J. (2005). Flow. In Elliot, A. (ed.), Handbook of competence and motivation. New York: The Guilford Press.

[9] Egbert, J. (2003). A study of flow theory in the foreign language classroom. The Modern Language Journal, 87, $499-518$.

[10] Grabe, W. and F. Stoller. (1997). Content-based instruction: Research foundations. In M.Snow \& D.Brinton (ed.), The contentbased classroom perspectives on integrating language and content. White Plains, NY: Longman.

[11] Higher Education Department of Education Ministry. (2004). College English curriculum requirements (For Trial Implementation). Shanghai: Shanghai Foreign Language Education Press.

[12] Higher Education Department of Education Ministry. (2007). College English curriculum requirements. Beijing: Foreign Language Teaching and Research Press.

[13] Hoffman, D.L. and T.P. Novak. (1996). Marketing in hypermedia computer-mediated environments: conceptual foundations. Journal of Marketing, 60: 50-68.

[14] Lin, L. (2000). Study on second language acquisition. Beijing: Capital Normal University Press.

[15] Nakamura, J., and Csikszentmihalyi, M. (2009). Flow theory and research. In C. R. Snyder \& S. J. Lopez (ed.), Handbook of positive psychology. Oxford: Oxford University Press.

[16] Parncutt, R and McPherson, G. E. (2002). The science and psychology of music performance: creative strategies for teaching and learning book. Oxford: University Press.

[17] Snyder, C.R. and Lopez, S.J. (2007). Positive psychology: the scientific and practical explorations of human strengths. London: Sage Publications.

[18] Wright, S. "In the zone": enjoyment, creativity, and the nine elements of "flow". http://www.meaningandhappiness.com/zoneenjoyment-creativity-elements-flow/26/ (accessed 10/11/2012).

[19] Webster, J., Trevino, L. and Ryan, L. (1993). The dimensionality and correlates of flow in human-computer interactions. Computers in Human Behavior, (9), 411-426.

[20] Young, J. A. and Pain, M. D. (1999). The zone: evidence of a universal phenomenon for athletes across sports. Athletic Insight, 3(1), 21-30.

Xiaowei Guan was born in Shenyang, China in 1979. She received her PH.D. in machine translation from Dalian University of Technology, China, in 2009.

She is currently a lecturer in the School of Foreign Languages, Dalian University of Technology, Dalian, China. Her research interests include machine translation and natural language processing, E-C and C-E translation and contrast. 